\title{
Verrucous carcinoma of the anus containing human papillomavirus type 16 DNA detected by in situ hybridisation: a case report
}

\author{
Fuju Chang, O Kosunen, V-M Kosma, S Syriänen, J Lahtinen, K Syrjänen
}

\begin{abstract}
Verrucous carcinoma of the anus is a distinct and rare variant of well-differentiated squamous cell carcinoma. A case of anal verrucous carcinoma in a 35 year old man was studied by light microscopy and in situ DNA hybridization. Human papillomavirus (HPV) type 16 DNA sequences were demonstrated in the tumour cells, as well as in cells showing koilocytotic and dyskeratotic changes. The possible viral (HPV) aetiology of verrucous carcinoma is considered with a review of the previous literature.
\end{abstract}

Verrucous carcinoma, a clearly defined variant of squamous cell carcinoma, was first described as an entity in 1948 by Ackerman. ${ }^{1}$ It has most frequently been reported in the oral cavity, ${ }^{1-4}$ the larynx, ${ }^{25}$ skin; ${ }^{67}$ but sometimes arises also in the anogenital area. ${ }^{28-9}$ Anal verrucous carcinoma is an extremely rare lesion; so far only 10 cases have been reported in the English literature. ${ }^{10-14}$ The unique and rather characteristic clinical course of the verrucous carcinoma and its distinct gross and microscopic features have been extensively described by a number of authors. ${ }^{1-14}$ Generally, this tumour has an exophytic warty appearance; it tends to grow slowly and appears microscopically as an extremely welldifferentiated squamous cell carcinoma which is locally invasive but nonmetastasing. ${ }^{1-9}$ The aetiology of verrucous carcinoma is not established for sure. Because of the morphological similarities to the condylomatous lesions known to occur frequently in the anal region, ${ }^{15}$ it has been suggested that verrucous carcinoma may share the viral aetiology of benign

Kuopio University Central Hospital, University of Kuopio, Kuopio, Finland

Department of Pathology and Kuopio Cancer Research Centre

Fuju Chang, S Syrjänen, K Syrjänen

Department of Pathology

O Kosunen, V-M Kosma, K Syrjänen

Department of Surgery

J Lahtinen warty lesions, that is, is caused by human papillomaviruses (HPV). ${ }^{96-20}$ We present here a case of anal verrucous carcinoma in which abundant $H P V$ 16 DNA sequences were demonstrated by in situ DNA hybridisation.

\section{Case report}

A 35 year old man was submitted into Kuopio University Central Hospital in November 1989 with the complaint of an exophytic tumour in the anal region. The tumour had been in its place more than five years, but during the last few months, it had

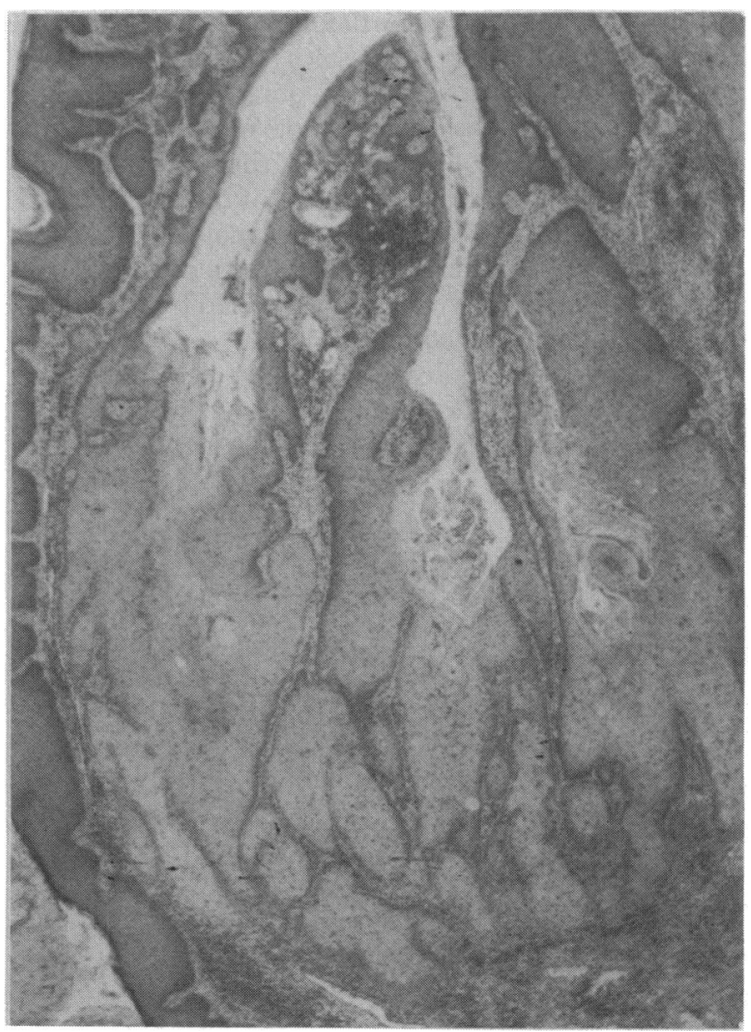

Figure 1 A low-power photomicrograph of the anal verrucous carcinoma characterised by papillomatosis, acanthosis, parakeratosis and hyperkeratosis. Invading edges are broad and rounded (haematoxylin and eosin; $\times 40$ ). 
begun to grow and to cause pain. The tumour did not interfere with the patient's defecation, and there was no dysuria. So far, no data on patient's eventual homosexual behaviour or results of HIV test are available.

On gross examination, there was an exophytic mass involving the perianal skin, measuring $2 \times 3$ $\mathrm{cm}$. The tumour was gray-white, rough surfaced and warty in appearance. Redical excision of the tumour was carried out, and the material was submitted for histopathological examination.

Histological sections were stained with haematoxylin and eosin. Microscopic examination revealed the morphological features consistent with a verrucous carcinoma. The tumour was composed of papillary fronds of well-differentiated squamous epithelium with extensive hyperkeratosis and parakeratosis (or superficial dyskeratosis) (fig 1). The epithelium was hyperplastic and penetrated into the underlying tissues in broad bulbous downgrowths, that is, was pushing rather than infiltrating. The cells in the superficial and intermediate layers showed extensive koilocytotic changes morphologically identical to those of condylomatous lesions (fig 2). The

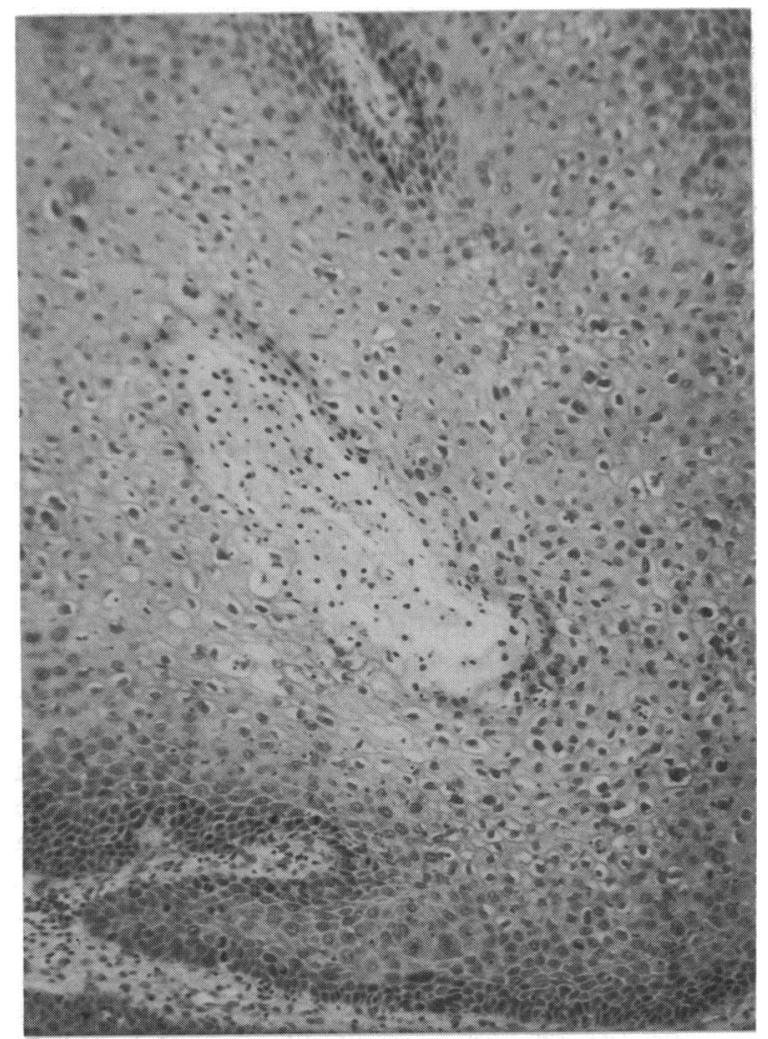

Figure 2 A medium-power photomicrograph of the lesion showing dyskeratosis of the superficial cell layers and extensive koilocytosis in the mediate cell layers (haematoxylin and eosin; $\times 100)$. tumour stroma was infiltrated by abundance of chronic inflammatory cells.

In situ hybridisation on paraffin-embedded sections using ${ }^{35} \mathrm{~S}$-labelled HPV DNA probes was performed as detailed previously. ${ }^{21}{ }^{22}$ DNA probes of HPV types 6, 11, 16, and 18 were kindly provided by Professor H. zur Hausen (Deutsches Krebsforschungszentrum, Heidelberg, FRG). Abundant HPV 16 DNA sequences were demonstrated particularly in the superficial epithelium which correlated well with the presence of condylomatous lesions, as indicated by the black silver grains superimposed on nuclei of koilocytotic and dyskeratic cells. In addition, HPV 16 DNA sequences were found in the cancer cells as well (fig 3).

\section{Discussion}

Anal verrucous carcinoma is a rare disease, and the case reports published so far are much fewer than those related to oral, larynx and external genitalia. ${ }^{11}$ The clinical and morphological features of anal verrucous carcinomas are similar to those in the other anatomical sites..$^{10-14}$ Clinically, it shows a slowlygrowing course and a relatively favourable prognosis with little metastatic potential. The histopathological changes include a thickened papillary epithelium showing hyperkeratosis and parakeratosis in the upper layers, and acanthosis in the underlying layers. The epithelium is well-differentiated, and usually forms large bulbous rete ridges with well-demarcated borders pushing into the underlying stroma.

However, the diagnosis of verrucous carcinoma in the 'anogenital area may encounter problems both clinically and histologically. ${ }^{9}$ Differential diagnosis, including condylomata acuminata, giant condyloma acuminatum (also known as Buschke-Löwenstein tumour), pseudo-epitheliomatous hyperplasplasia as well as keratinising squamous cell carcinoma, has been thoroughly discussed by a number of previous authors. ${ }^{23592324}$

The aetiology of verrucous carcinoma is not generally agreed. In the oral cavity it has been previously related to cigarette smoking and tobacco chewing, to poor oral hygiene, or poor dentation..$^{2-4}$ Penile lesions, on the other hand, have been linked with the presence of redundant prepuce, poor hygiene, or preexisting condylomata acuminata. ${ }^{23}$ Of particular interest is the possible viral aetiology of verrucous carcinoma. The histological appearance, that is, papillomatosis, koilocytosis, acanthosis and superficial dyskeratosis found in verrucous carcinoma, seems to bear a close resemblance to the cytopathic changes caused by HPV. ${ }^{9}$ Okagaki $^{24}$ examined 12 of 27 cases of vulvar verrucous carcinoma by electron microscopy and found eight cases with intranuclear HPV-like particles in the superficial layer of the epithelium. Similar results 


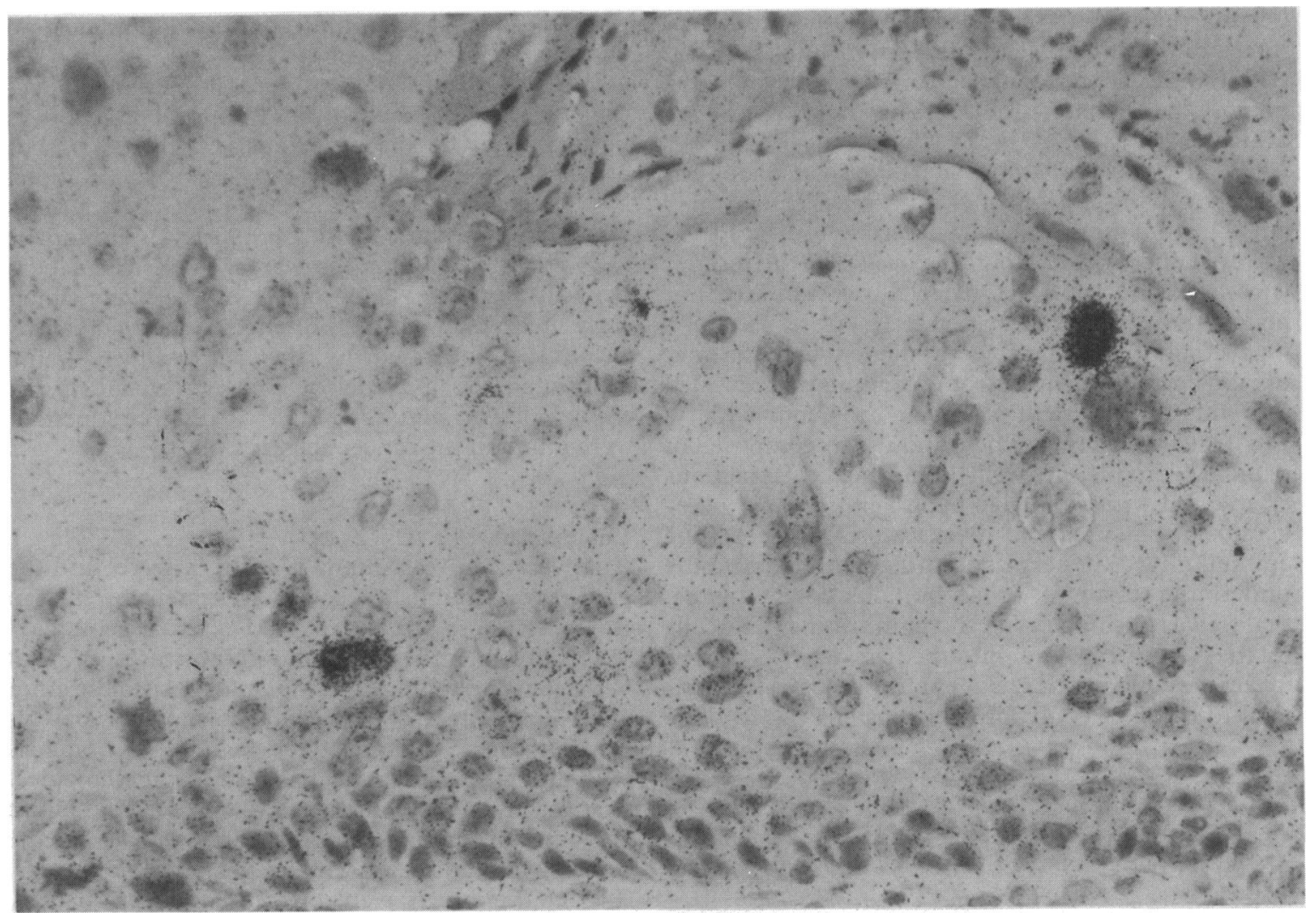

Figure 3 A high power view of the lesion in situ DNA hybridisation with HPV 16 DNA probe under stringent conditions. The black silver grains after autodiography are found superimposed on nuclei of scattered tumour cells showing dyskeratic and koilocytotic changes (haematoxylin counterstain; $\times 250$ ).

were reported also in cervical ${ }^{18}$ vaginal $^{11}$ and penile ${ }^{25}$ verrucous carcinomas. Recently, Blessing et al ${ }^{12}$ examined three cases of verrucous carcinoma (one perineal, one penile and one laryngeal); all of them showed HPV capsid proteins with immunoperoxidase technique. More recently, HPV type 6,11 and 16 DNA sequences were demonstrated in verrucous carcinomas of the larynx $x{ }^{16}$ vagina ${ }^{20}$ and vulva. ${ }^{17}$ The presence of HPV 16 DNA sequences in the present case of anal verrucous carcinoma by in situ DNA hybridisation further supports the concept that verrucous carcinoma might share a common viral aetiology with condylomatous lesions.

It is noteworthy that strong evidence has been provided during the past few years implicating an important aetiological role of HPV infection in the development of anogenital intraepithelial neoplasia and squamous cell carcinoma. ${ }^{1526-28}$ There have been many case reports of anogenital intraepithelial neoplasia and carcinoma in situ with condylomatous lesions in or in the adjacent mucosa. Similarly, numerous reports on malignant transformation of the anogenital condylomata and giant condylomas have been published. ${ }^{26-28}$ With histopathological assessment, Taxy et al ${ }^{29}$ found that 10 of 16 cases of anal squamous cell carcinoma were associated with condylomatous changes. Using Southern blot and dot blot hybridisation techniques, Palmer et al ${ }^{30}$ recently analysed a large group of anal squamous cell carcinoma. HPV 16 DNA sequences were detected in 23 of 41 and HPV 18 in 2 of 41 cases; no detectable HPV 6 or 11 DNA sequences were found in these malignancies. These findings have close parallels with genital squamous cell carcinomas and further support the concept of the involvement of HPV 16 and 18 in development of anal squamous cell carcinoma.

Therefore, the different morphological lesions, i.e. condylomata acuminata, giant condyloma acuminatum and verrucous carcinoma (and perhaps squamous cell carcinoma) could be interpreted as closely related entities, probably caused by HPV infection, and thus may represent a continuous spectrum of the same process, HPV-induced squamous cell carcinogenesis. 
Correspondence to: Dr Fuju Chang, Department of Pathology, University of Kuopio, P.O.B. 6, SF70211 Kuopio, Finland.

1 Ackerman LV. Verrucous carcinoma of the oral cavity. Surgery 1948;23:670.

2 Kraus FT, Perez-Mesa C. Verrucous carcinoma: clinical and pathologic study of 105 cases involving oral cavity, larynx and genitalia. Cancer 1967;19:26-8.

3 Goethals PL, Harrison EG, Devine KD. Verrucous squamous carcinoma of the oral cavity. Am J Surg 1963;106:845.

4 Fonts EA, Greenlaw RH, Rush BF, Rovin S. Verrucous squamous cell carcinoma of the oral cavity. Cancer 1968;23:152-60.

5 Ferlito A. Diagnosis and treatment of verrucous squamous cel carcinoma of the larynx: a critical review. Ann Otol Rhino Laryngol 1985;94:575-9.

6 Brownstein MH, Shapiro L. Verrucous carcinoma of skin Epithelium cuniculatum plantare. Cancer 1976;38:1710-6.

7 Klima M, Kurtis B, Jordan PH. Verrucous carcinoma of skin. $J$ Cutan Pathol 1980;7:88-98.

8 Partridge EE, Murad T, Shingleton HM, Austin JM, Hatch KD. Verrucous lesions of the female genitalia: II. Verrucous carcinoma. Am J Obstet Gynecol 1980b;137:419-24.

9 Väyrynen M, Romppanen T, Koskela E, Castren O, Syrjänen K. Verrucous squamous cell carcinoma of the female genital tract. Report of three cases and survey of the literature. Int J Gynecol 1981;19:351-6.

10 Gingrass PJ, Bubrick MP, Hitchcock CR, Strom RL. Anorectal verrucous squamous carcinoma: report of two cases. Dis Colon Rectum 1978;21:210-2.

11 Bogomoletz WV, Potet F, Molas G. Condylomata acuminata, giant condyloma acuminatum (Buschke-Löewenstein tumor) and verrucous squamous carcinoma of the perianal and anorectal region: a continuous precancerous spectrum? Histopathology 1985;9:1155-69.

12 Drut $R$, Ontiveros R, Cabral D. Perianal verrucous carcinoma spreading to the rectum: report of a case. Dis Colon Rectum 1975;18:516-21

13 Prasad L, Abcarian H. Malignant potential of perianal condyloma acuminatum. Dis Colon Rectum 1980;23:191-7.

14 Prioleau PG, Santa Cruz DJ, Meyer JS, Baeur WC. Verrucous carcinoma: a light and electron microscopic, autoradiographic and immunofluorescence study. Cancer 1980;45:2849-57.

15 Syrjänen MS, von Krogh G, Syrjänen KJ. Anal condyloma in men. 1. Histopathological and virological assessment. Genitourin Med 1989;56:216-24.

16 Abramson AL, Brandsma J, Steinberg B, Winkler B. Verrucous carcinoma of the larynx. Arch Otolaryngol 1985;111:709-15.

17 Crowther ME, Shepherd JH, Fisher C. Verrucous carcinoma of the vulva containing human papillomavirus-11. Case report. Br J Obstet Gynecol 1988;95:414-8.

18 Maeyama M, Fukuma $K$, Tanaka N, Inoue $S$, Tooya T. A case of verrucous carcinoma of the uterine cervix: clinical, light and electron microscopic, and immunohistological observations. Gynecol Oncol 1985;22:244-9.

19 Blessing K, McLaren K, Lessells A. Viral aetiology for verrucous carcinoma. Histopathology 1986;10:1101-3.

20 Okagaki T, Clark BA, Zachow KR, et al. Presence of human papillomavirus in verrucous carcinoma (Ackerman) of the vagina. Arch Pathol Lab Med 1984;108:567-70.

21 Syrjänen S, Syrjänen K. An improved in situ DNA hybridization protocol for detection of human papillomavirus (HPV) DNA sequences in paraffin-embedded biopsies. J Virol Methods 1986;14:293-304.

22 Syrjänen S, Partanen P, Mäntyjärvi R, Syrjänen K. Sensitivity of in situ hybridization techniques using biotin- and ${ }^{35} S-$ labelled human papillomavirus (HPV) DNA probes. $J$ Virol Methods 1988;19:225-38.

23 Powell JL, Franklin EW, Nickerson JF, Burrell MO. Verrucous carcinoma of the female genital tract. Gynecol Oncol 1978;6:565.

24 Okagaki T. 'Warty carcinoma' of the vulva: A probable implication of human papilloma virus as the causative agent. Lab Invest 1981;44:49a.

25 McKee PH, Lowe D, Haigh RJ. Penile verrucous carcinoma. Histopathology 1983;7:897-906.

26 zur Hausen $H$. Human papillomaviruses and their possible role in squamous cell carcinomas. Curr Top Microbiol Immunol 1977;78:1-30.

27 Gissmann L. Papillomaviruses and their association with cancer in animals and in man. Cancer Surv 1984;3:161-81.

28 Syriänen K. Human papillomavirus (HPV) infections of the female genital tract and their association with intraepithelial neoplasia and squamous cell carcinoma. Pathol Annu 1986;21:53-89.

29 Taxy JB, Gupta PK, Gupta JW, Shah KV. Anal cancer: Microscopic condyloma and tissue demonstration of human papillomavirus capsid antigen and viral DNA. Arch Pathol Lab Med 1989;113:1127-31.

30 Palmer JG, Scholefield JH, Coates PJ, et al. Anal Cancer and human papillomaviruses. Dis Colon Rectum 1989;32:1016-22.

Accepted for publication 31 May 1990 